\title{
Why Failed So Often the Offset Part of a Defence Procurement Deal? - A Case Study Based Examination
}

\author{
Heinz Kirchwehm (Corresponding author) \\ Faculty of Business Administration, Turiba University \\ 68 Graudu Street, Riga, LV-1058, Latvia \\ E-mail: h.kirchwehm@web.de
}

Received: July 04, 2014 Accepted: August 13, 2014 Published: September 8, 2014

doi:10.5296/bms.v5i2.6283 URL: http://dx.doi.org/10.5296/bms.v5i2.6283

\begin{abstract}
An offset obligation is a countertrade which must be accepted in order to win the contract for a superior procurement project. This type of countertrade takes mainly place by government to government and commercial sales in the aerospace and defense business. Offset can be executed in the form of industrial, commercial and political agreements and serves essentially to meet the socio-economic objectives of the buying side. Therefore that today nearly every larger procurement project has offset obligations is the composition of the offered offset package the main distinguishing criterion between the various competitors. The value of such an offset package is accounting a multiple value of the actual procurement project. So, there are many good reasons for the successful execution of offset projects. Nevertheless we have the situation that offset projects are failing! Therefore, with view on the still large amount of outstanding offset projects, it is of great importance for the companies to know the reasons why offset projects are failing. The aim of this paper is to examine the specific circumstances of failing offset projects as part of defence procurement deals. This examination was triggered through a superior research project on the impact of offset at the business processes of SMEs. During the Pre-Study for this research project first indications come into view that not all offset related projects can be finalized successful. The paper concludes with a representation of the offset-specific reasons for the failing of such projects. Furthermore, it also provided the determinants of offset success to avoid these problems in future projects.
\end{abstract}

Keywords: Offset, Failing projects, Generic and specific project problems, Countermeasures 


\section{Introduction}

\subsection{What is Behind the Phenomenon Offset?}

An offset obligation is an countertrade which must be accepted in order to win the contract for a superior procurement project. This type of countertrade takes mainly place by government to government and commercial sales in the aerospace and defense business. Offset can be executed in the form of industrial, commercial and political agreements and serves essentially to meet the socio-economic objectives of the buying side. Therefore that today nearly every larger procurement project has offset obligations is the composition of the offered offset package the main distinguishing criterion between the various competitors. The value of such an offset package is accounting a multiple value of the actual procurement project. Despite all this includes offset for the selling side some advantages, especially is here to name the generation of new businesses. For not so experienced companies is the fulfillment of offset obligations a great hurdle, which is expressed by the sub-optimal project execution.

\subsection{What is Its Significance?}

As mentioned above are serving worldwide the differently configured offset packages the procurement authorities as one of the main distinguishing feature for the assessment of defense procurement projects. The subject offset is therefore from the beginning part of the acquisition process and requires from all involved participating sides due to the complexity of the subject a high level of abstraction ability to appraise all pros and cons. This is not makeable for every company which is offering for high value procurement projects. Nevertheless, in today's modern business is offset an important fact which can generate benefits for both sides when it is careful planned and negotiated (Tricolum, 2014):

A.) For the buying side:

- The government can define their socio-economic objectives and can use offset for the realization of it $\rightarrow$ political advantages.

- The government can develop specific the economic and industrial base of the country $\rightarrow$ economic benefits.

- Through the transfer of technology, the access to new markets and the relocation of work, the local employment opportunities can also be specifically improved $\rightarrow$ economic benefits.

B.) For the selling side:

- Offset can generate a greater benefit by activating of new global supply chains.

- Offset can also be a way to diversify the business.

- Offset is a tool to enter into new markets.

- Offset is a tool to differentiate themselves from the competition and win new business

\subsection{Need for Action}

In the period from 2003 to 2010, the volume of the global unfulfilled offset obligations was around $\$ 50 \mathrm{bn}$. It is anticipated that they will double by the end of the decade. The problem 
for most of the supplier is that the fulfillment of offset obligations is not part of their core business. Through the fact that the non-fulfillment of offset obligations is linked with penalties represents this potential risk for the involved companies. The amount of the global offset obligations is raised so much in the recent years that the companies have problems with the timely fulfillment. This leads to the so-called offset-gap. This situation is getting even critical by the fact that we have everywhere different national regulations on the subject offset and it is therefore up to the parties to negotiate the terms of delivery, penalties, and so on. Consequences which are arising from the non-fulfillment of offset obligations are (Tricolum, 2014):

A.) For the selling side:

- The supplier loses its credibility.

- More business deals are thus unlikely.

- Penalty payments can lead to a financial risk.

- The buyer can refuse partial deliveries from the main contract.

- $\quad$ The "bid to win" ratio can get worse.

B.) For the buying side:

- Possible impact on the economy.

- No positive incentives to local business

- Loss of credibility in offset requiring future procurement programs where is required.

In order to avoid the highlighted risks can the selling side outsource the fulfillment of offset obligations to third parties. So, there are many good reasons for the successful implementation of offset projects. Nevertheless we have the situation that offset projects are failing! Therefore, with view on the still large amount of outstanding offset projects, it is of great importance for the companies to know the reasons why an offset project failed. This knowledge gap needs to be closed, especially due to the fact that increasingly companies are faced with the issue of offset which have so far no points of contact with it.

\section{Theoretical Framework}

\subsection{The Most Disseminated Academic Definitions of Offset}

In 2002, Dr. J. Brauer evaluated numerous offset definitions which have been offered up to that point in the literature. Here in particular the work of Neuman in 1985, the work of Udis and Maskus from 1991 and as well the work of Hartley from 1995. All definitions are in his opinion inherent, that they contain a certain amount of coercion for the selling side. Short: Without offset any procurement program. However Brauer stated also, supported by Hall and Markowski (1994), that a seller is never forced to sell and therefore the offset obligation is accepted voluntarily (Hall and Markowski, 1994 Brauer, 2002).

\subsection{The Different Types of Offset}

Offset exists in two different ways. The first one is the direct offset which requires so-called foreign direct investments (FDI) in partnerships with companies of the buying side and 


\section{Macrothink}

Business Management and Strategy

ISSN 2157-6068

2014, Vol. 5, No. 2

remains connected to the actual procurement project. The idea is to set the trigger for a later independent production of weapon systems. Meanwhile, there are several positive examples of such independence by successful realization of offset. These are, among others, the examples of South Korea and Turkey. Indirect offset is not directly connected to the procurement project. It covers everything from transfer of new technologies, the development of business parks, and the construction of hotels and shrimp farms (Economist, 2013). The goal of this offset form is to improve the overall economic base of the buying side.

\subsection{The Various Categories of Offset}

Beside the classification of offset by type (direct or indirect) the individual components of offset are divided into different categories, which describe more precisely the contexts of the different activities. According to BIS (2007) these categories are:

- Purchases

- Subcontracts

- Technology Transfers

- Credit Assistance

- $\quad$ Training

- Overseas Investment

- Co-production

- $\quad$ Licensed Production

- Miscellaneous

The Figure below shows that each category is considered direct, indirect, or could be either one (e.g., Technology Transfer, Training).

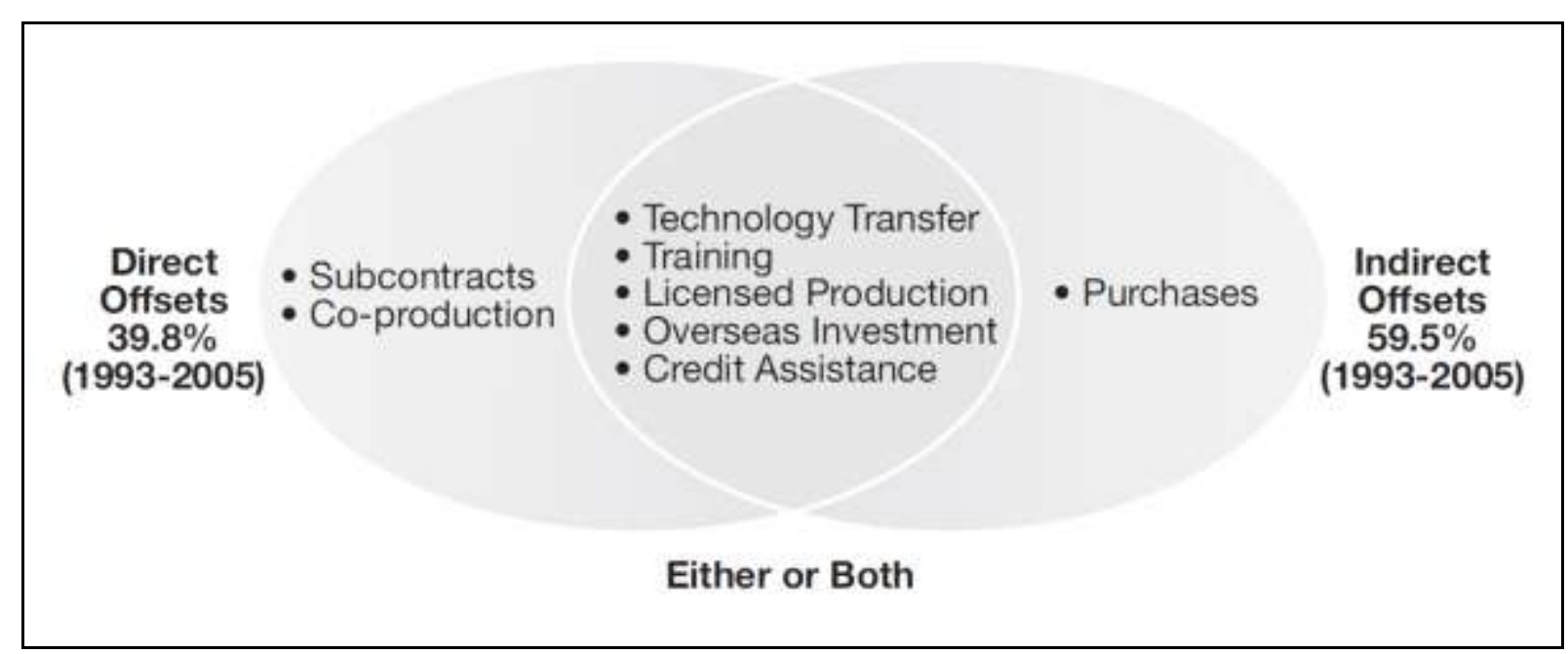

Figure 1. Offset categories (BIS 2007, p. 45) 
Because of their dominance, the two offset categories Purchasing and Subcontracting are in detail explained on the example of the United States of America (BIS, 2007):

Purchases result for the buying side to a production of goods or services, which are usually determined for export to the selling side. Purchases are classified as indirect offsets, to distinguish them from sub-contracting, due to the fact that these purchases are not directly related to the procured weapon systems. The selling side can make these purchases by themselves, or they can handle it via broker what leads than to purchases by third parties. In the period of 1993 to 2005 purchases generates a share of $37.9 \%$ of the actual value of all offset transactions and is therefore ranked on the first place of any other offset category.

$>$ Offset related subcontracts result for the buying site to the production of goods or services which are then an integral part of the purchased weapons system. Subcontracts are classified as direct offset. In the period 1993 to 2005 subcontracts accounted for more than one-fifth of the actual value of all offset transactions.

\subsection{Which Generic Problems are Causing a Failed Project}

Ideally, each Project will be "on time" and "within budget" completed. In reality, it looks different. In project business, it is not unusual when a project failed. And even when a project is completed within the scheduled time and with the related forecasted costs, the question remains, "Has the project delivered the results and the quality which were expected?" Only when all 3 success criteria have been met (on time, within budget, in quality), a project can be considered as successful. There are many reasons why a project is failing; the number of reasons is almost endless. Subsequently, the attempt to list the most common reasons for the failure of projects:

- Poorly managed

- Undefined goals

- Lack of management support

- Lack of project plan

- Lack of end-user involvement

- Lack of support within the organization

- Poorly defined roles and responsibilities

- Vaguely defined requirements

- Stakeholder disagreements

- Team weakness

- Unrealistic time pretending

- Conflicting prioritization

- Inadequate communication 
- Inadequate resources (financial and personnel)

- Lack of project portfolio management

- Scope Creep

- Lack of change management process

- Ignoring warning signs in the project

- Insufficient testing processes

- Inadequate consideration of interference

Even with the best intentions and solid project plans projects can fail if they are not properly managed. Mishaps occur during the project. At this point, the project manager comes into play and must respond. The project manager must be able to see the difference between symptoms and problems and to have a sense of when a project sends out warning signals. It is therefore primarily on the personality of the project manager when it comes to project success or failure. His personal capability determines the weal and woe of the project, by using the success factors for project management. Furthermore, the continuous increase of complexity on both sides of selling and buying side requirements to all project participants.

In addition to the generic project problems explained above, there are certainly offset specific problems which are caused in a failed project. These should be examined in the following.

\section{Methodology}

\subsection{Aim of This Examination}

The aim of this paper is to examine the specific circumstances of failing offset projects as part of defence procurement deals. For the fulfillment of this aim, the following research tasks arise:

1. Analyzing the consequences of not fulfilling the offset projects.

2. Analyzing the generic reason for project failing.

3. Describe various non-functional offset projects (case study 1 to 4 ) to understand the complex situation of such an offset project.

4. Deriving from the cases studies the offset-specific reasons for the failure of such projects.

\subsection{Research Framework and Methodical Approach}

This examination was triggered through an overall research project on the impact of offset at the business processes of SMEs. During the necessary Pre-Study for this research project first indications appear that not all offset related projects can be finalized successful. But to the still increasing amount of offset projects is it essential for companies to know which offset specific problems caused in a failing project. 
The execution of the research tasks is done with the help of a so-called case study examination. According to Harrison (2002) is a "(...) case study research of particular value where the theory base is comparatively weak and the environment under study is messy." Harrison (2002, p. 159). Both of these criteria were relevant to this paper. The extant literature basis on the subject offset is quite good but an analysis of the specific project problems is still outstanding. In addition is the defence industry an industry where vulnerable information like project data, etc. will not be published. Here is the starting point of this case study examination. By determining that the focus of this examination is on failing offset projects, the author was able to select the right cases to study. Best cases in practice actually mean not only the best environment for exhibiting the phenomenon under study, but also the best from a point of view of ease access (Ibid, p. 171).

For this examination four different offset projects became selected: US Fighter planes for several countries, an example of a offset project with negative consequences, F-16 for Poland and Arms-Offset Projects Fail to Deliver in South Africa. In principle, any failed offset project could be selected. In case of these four projects can be assumed that they represented a quit good cross section on failed projects, so that the results could be generalized. Another reason for selecting these four projects is the fact that these case studies are good publicly documented and accessible.

\section{Validity of the findings}

Due to the low number of examined case studies, the statements made here have of course only a limited explanatory power. Nevertheless, the case studies will show the specific problems in the execution of offset obligations.

\subsection{Methodical Approach}

The examination has been undertaken in four phases.

Phase One was a literature review which was conducted to find out the consequences of not fulfilling the offset projects and of the generic problems in project execution.

Phase Two was the description of various non-functional offset projects to understand the complex situation of such an offset project

Phase Three consisted the analyzing of the case studies to match what general and what are specific problems, so that from the cases studies could deriving the offset-specific reasons for the failing of such projects.

Finally, Phase Four involves the derivation of determinants of offset success for avoiding of these problems in the execution of offset projects.

\section{Examples of Unsuccessful Offset Projects}

\subsection{US Fighter Planes for Several Countries}

The following case is very detailed describe by Lora Lumpe in the year 1994 in the article Sweet Deals, Stolen Jobs: The outlined offset deal "U.S. Fighter planes for several countries" 
describes impressively the problems of the US-American aviation industry in terms conducting offset deals. The with $\$ 5.2$ billion rated offset deal about the Korean Fighter Program (KFP) in 1991 points typical problems of offsets. South Korea bought 12 off-the-shelf F-16C/D from General Dynamics and as well further 36 aircraft kits which should be assembled in Korea. Due to the fact that South Koreas intend was to produce an indigenous fighter aircraft, it applied the rights to produce under license an additional set of 72 F-16. However, to cover the necessary production capacity was not enough by far. Although Korean Air Lines and Daewoo Heavy Industries had already produced some F-16 parts, and Samsung Aerospace produced parts for the F/A-18 but that manufacturing capability was nothing "compared to the level of manufacture and production line management contemplated under the KFP," according to the General Amounting Office. The problem was exacerbated by the fact that Korea received $\sim 30 \%$ of the contract value - more than $\$ 1.5$ billion - in undisclosed indirect offsets. Indirect offsets may be what the member of United States House of Representatives Ron Wyden, an Oregon Democrat, had in mind when he called some deals "just bizarre" during a 1985 Congressional hearing. Therefore this 30 percent volume was also not useable to build up the necessary know-how of manufacturing capacity to build an indigenous fighter aircraft.

The McDonnell Douglas Group accepted in 1982 for a $\$ 1.8$ billion sale of F/A-18 fighters to Spain an offset obligation package with the value of $\$ 1.5$ billion. McDonnell Douglas had agreed to market a wide selection of Spanish products in the United States, including chemicals, sunflower oil, steel coils sailboats, zinc, marble and paper products. Within this offset deals perhaps one of the strangest offsets was realized due to fact that McDonnell Douglas helped in setting up a Domino's Pizza franchise in Barcelona.

\section{$\underline{\text { Summary on this case }}$}

From the case study described above, two serious problems in the execution of offset projects can be derivate. First is there the totally underrated situation in the recipient country with a non-performance production infrastructure. In short: too much and all at once. Second, the totally inadequate execution of indirect offset obligations. The chosen projects didn't met the requirements of the Market (lack of attention for the sustainability of the offset project) and as well the requirements of the customers.

\subsection{An Example of a Offset Project with Negative Consequences}

Very useful for the context of this paper is also the view on the impact of offset on the companies of the participating industry. Beside the major offset projects we have also the situation that the offset projects causing problems for the involved company. Here we look on an example from the Switzerland which is published by the Swiss Federal Finance Controll (SFFC) in 2007.

The company named $\mathrm{C}$ was active for many years in the engineering, electrical and metal industry. The company appeared above average in a number of offset projects either as parts supplier in connection with offline businesses or for the delivery of standard components in the context of direct investments. The offset related revenue has increased to $25 \%$ in the last 
years. The loss of one of the large offset orders of the last years brought the company $\mathrm{C}$ in a difficult position. In addition to that they had missed to drive innovation in their company as well as to modify the necessary structural adjustments. Because of the no longer competitive product portfolio, the company $\mathrm{C}$ had no chance to compensate the loss of the substantial high revenues from offset transactions (over $25 \%$ of total sales). After three more years with almost no offset they disappeared entirely from the scene and reported a short time later that they are bankruptcy.

\section{$\underline{\text { Summary on this case }}$}

The example above shows that even a so-called sub-offset-project can fail if the involved companies focus too much on the offset transactions and these are then not continued as expected. A unilaterally business model!

\subsection{F-16 for Poland}

This case results from several internet resources and describes impressively two serious problems of offset.

In the year 2005 has Poland conducted a competition between the Mirage 2000-5 Mk.2, the JAS 39 Gripen, the MiG-29 and the F-16 Falcon to replace their aging fleet of Soviet-built MiG-23 and the MiG-21 fighters. The result was that Poland purchased 48 F-16C/D-52+ aircraft from Lockheed Martin which were delivered from 2006 under the PEACE SKY program, to avoid confusion with the PZL W-3 (Polish language "Falcon") helicopter. Beside others models is now the F-16 the main offensive strike force for Polish Air Force. But there were problems with the introduction of the Polish F-16s and they were often grounded with technical defects (F-16.net, 2007). The linked offset deal is also not running so well, because Lockheed Martin has not made all the declared investments in Poland that were part of the deal. At the time when offer was chosen an offset value of $\$ 9.8$ billion was declared. In the year 2011 have the value of offset deals reached the level of $\$ 6$ billion out of $\$ 6.028$ billion planned. Only one-third of identified offsets commitment were direct investments in Polish economy (BBC, 2008). A former Polish military defence vice-minister expressed themselves, that from his view the offer for JAS 39 Gripen was a better deal (Konflikty, 2007). The cost for the F-16s was $\$ 3.5$ billion compare to only 3.2 billion euro for Saab's Gripen and 3.6 billion euro for the offer from Dassault, at that time both currency had the same value (Bankier, 2008). Poland's choice of purchasing 48 Lockheed Martin F-16 fighters was designed to stimulate a decade of American investment into this country, but several projects have failed to materialize at an early stage, such as the Grupa Lotos refinery technology license project. One of the successfully projects in attracting foreign direct investment, is the relocation of as General Motors production facilities from Germany to Gliwice in southern Poland.

\section{Summary on this case}

From the case study described above, two serious problems in the execution of offset projects can be derivate. First is there the lack of necessary skills of the by offset participating industry due to a poor or no successful know-how transfer. Second, promises cannot be 
fulfilled with respect to the required offset obligations. Unconscious or even intentional underestimation of opportunities to fulfill.

\subsection{Arms-Offset Projects Fail to Deliver in South Africa}

This case is well reported by Wyndham Hartley in the year 2004 and is typical for so many offset projects: In this case we look on a company which should participate from an offset affected defence procurement deal. In 2004 we have the situation that almost all of the defense offset projects which are linked to the state arms manufacturer Denel are loss-making and in the process of being renegotiated, reported by Denel CEO Victor Moche. According to the defense committee of the Parliament have we the situation that the by the offset projects earned margins were low or non-existent. In recent months, parliamentary committees have that the projects are $12 \%$ faster than planned, but nothing was mentioned regarding the profitability and whether the expected provision for growth and employment.

One example was the work done in a joint venture with Snecma Turbomecca. A failure of the Failure; due to the fact that the French robbing the contracts of profitability. What was the reason? The calculations of the French were based on the hypothesis of certain costs in South Africa, but do not take into account the circumstance that steel was, for example, in South Africa as the same in France. The whole calculation based on an estimated South Africa price.

Mr. Moche stated also that it was necessary to rewrite and change some of the contracts which Denel have with Eurocopter and Augusta, SAAB the Gripen, where they find the counter-committed and modified it in the way that they can reach an break even. The difficulty was hereby that people are making a lot of money so they are not happy to change that.

Also told Mr. Moche the committee that the relations between Denel and Armscor were tense. He wants that the acquisition role of Armscor and the marketing role of Denel to be clarified. In addition he indicts Armscor to sell the same product for different customers by Denel at a different price. The evidence is the case India, where afterwards the market was confused.

\section{Summary on this case}

In the case of South Africa essential questions were not asked and answered prior to the offset-linked procurement:

$>$ Is the necessary level of infrastructure set up and is also the right support from the government agreed? A large group of people is outside the government who do not believe that the procedure is performed or supervised properly. While government has repeatedly tried to adapt their policies, there are discrepancies that arise, such as the rising cost and conflicting reports about offset achieved so far. This and the unclear assertions of the government regarding the decision-making process for selecting the prime contractors.

$>$ Is there a need for this equipment in the country? In times when the country faces no direct threat is it an argument to deny any increasing armament of the armed forces. A 
large number of people is thinking that investments are spent better of other projects like social activities.

Are transnational companies sufficiently committed to developing the industrial base? Some people says that highly developed countries of the EU and the United States, are very successful to influence the international meaning regarding the arms trade, debt's and the development. The same people adds that nowhere is the contradiction between the development goals of the government and its foreign policy goals more at advantages than in its arms trade policy. In fact, these countries must been criticized due to their support on arms exports to developing countries, while at the same time they maintaining their support for debt relief. (Willett, 1999).

\section{Conclusion}

Based on the above presented examples of unsuccessful offset projects will be derivate in this chapter the offset-specific reasons for the failing of such projects. Furthermore are will be provided also determinants of offset success to avoid these problems in future projects.

\subsection{The Offset Specific Problems}

The problems associated with offset are complex and can begin in advance of the actual offset project. Symptomatic for this is the question which must be asked at the beginning: "Does the country need the equipment"? Because offset is not a "Sit modus est in"!

Two in several failed offset projects are arising problems are:

- The totally underrated situation in the recipient country with a non-performance production infrastructure.

- The lack of necessary skills of the through offset participating industry due to a poor or no successful know-how transfer.

Will this problem be avoided there is no longer a need to ask the following question: "Has the necessary infrastructure been put in place, and is there sufficient support from the government"?

The next serious problems are:

- The totally inadequate execution of indirect offset obligations. The chosen projects didn't met the requirements of the Market (lack of attention for the sustainability of the offset project) and as well the requirements of the customers.

- $\quad$ Promises cannot be fulfilled with respect to the required offset obligations. Unconscious or even intentional underestimation of opportunities to fulfill.

Will this problem be avoided there is no longer a need to ask the following question: "Are transnational companies sufficiently committed to developing a country"?

Offset projects can contain hidden problems which are not necessarily contribute to fail a single project, but what is even worse, to fail the entire company: 
- $\quad$ Even so-called sub-offset project can fail if the involved companies focus too much on the offset transactions and these are then not continued as expected. Unilaterally business model. $\rightarrow$ Lack of follow-up orders.

\subsection{Determinants of Offset Success}

Offset projects, which aims are defined as support to domestic industrial base (mainly the defence industry) and support to domestic economy follow two aims at the same time economic one and security related one. So, we can divide the expected success of requested offset benefits for a country importing weapons into two basic parts - benefits in a form of maintaining and/or strengthening domestic defense industrial base and benefits enhancing the performance of domestic economy as such. From this point of view, we can classify determinants of successful offset program as general, defense industry related and economic performance supporting. It is evident that to certain extent, defense industry related determinants can also influence performance of domestic economy, especially in a short term.

\section{The basic determinants}

First, achievement of expected results of any offset arrangement depends on the likelihood that the foreign contractor(s) will comply with its (their) commitment, usually spread over several years. Second, it depends on the fact whether or not offset execution generates new economic activity in the economy of the government importing weapons. This closely relates to the ability of this government to check achievements of the contractor as well as negotiate and enforce penalties in case the contractor fails to comply with given offset agreement.

\section{The determinants for the participating industry}

Expected benefits related to defense industry are dependent on many factors. First, it is the value of direct or semi-direct offsets where this category of offset transactions is viewed as those offset that aim purely at defense industry. Second, it is the extent to which the direct and semi-direct offsets are focused on segments of defense industry that are prospectively critical for armaments policy of the government importing weapons. This direct offset polarization encompasses for instance orientation towards, development, maintenance or production capabilities of domestic defense industrial base that match requirements formulated in national armaments strategy or other national armaments medium- or long-term plan. The last critical defense industry related determinant can be formulated as the stability of national armament policy. This determinant is closely related to long-term stability of national security policy, existence of balanced long-term defense plans and related stable funding schemes. Last but not least, it is necessary to consider the fact that offset requirements might cause an increase of prices for the armaments being purchased within the underlying contract.

\section{The determinants for the economic performance}

From the point of view of national accountancy, for a government requesting offsets, impact of these transactions on economic performance first of all depends on their value in relation to the value of their underlying contracts. So, the first economic performance related 
determinant can be formulated as the offset value proportion in the underlying arms contract price. Further, the effect of offsets on economic performance depends on the form of offset transactions included in given offset program. Co-production, licensed production and sub-contractor production relate mainly to direct offsets and represent works placed to domestic industry either with or without transfer of technical information. Thus, in a short term these categories of offsets will contribute to economic performance in a form of increased demand for domestic production. Their long-term effect will depend on the ability of the industry take advantage of the technical information acquired and the offset contracts to increase its competitiveness resulting in enhanced future activities. In a short-term, inward foreign investments induced by offsets directly increase gross domestic product in the form of stabilization of the balance of payments and potential increase of exports. Their long-term effects depend upon many factors like global development of given industry, related return rate of investments etc. The key effect of inward foreign investments rests in enhanced competitiveness connected with their multiplication effect and/or impact on employment rate. Competitiveness enhancement consists mainly in the fact that inward foreign investments bring new technologies and know-how (both technical and organizational) which increases productivity in the industry/economy.

\subsection{Critical Discussion of the Results}

The increasingly asking for offset obligations in defence procurement deal requires from the affected companies a consideration of the relevant specific problems and determinants of offset success for planning and execution of their offset-projects. This in turn makes necessary the implementation of all of these aspects in a strategy at company level. What brings now an offset strategy which based on the results of this examination? Firstly can be assumed, that problems such as a totally underrated situation in the recipient country, etc. can be avoided, due to the fact that this problem is now under consideration. However, the consideration of the above-identified determinants of offset success is not a guarantee that it comes not to problems in project execution as a result of unpredictable factors, such as personal animosity, and so on. Furthermore, the question arises if a final presentation of all the relevant problems and determinants of offset success can be generated only from the four used case studies? The answer will be $\underline{\text { NO}}$. A $\underline{\text { YES }}$ certainly requires a wider investigation.

\section{Conclusion}

This case study examination was triggered through an overall research project on the impact of offset on the business processes of SMEs, which will be published end of 2014. During the necessary Pre-Study for this research project first indications appear that not all offset related projects can be finalized successful. But to the still increasing amount of offset projects is it essential for companies to know which offset specific problems caused in a failing project.

The used methodology of a case study examination analyzing the worthwhile and replicable determinates of offset success to improve the way an organization operates their offset projects. The primary aim is to identify determinates that can be replicated elsewhere in the defence industry. Due to the selected number of case studies could be the results represented only an overview, but they adds to the already identified determinates of offset success in the 
extant literature.

During the work on this paper could the author observe again that the available literature on the subject offset is very limited in particular to its success factors. It is still a niche subject. Nevertheless dictates the constant increase of offset obligations that affected companies have to engage them with this subject and have study some specific aspects of them.

The aim of this paper is to examine the specific circumstances of failing offset projects as part of defence procurement deals. The implications of this examination are the concentrated display of the offset-specific reasons for the failing of such projects.

From the present study could be summarized the following: Offset is a complex subject and it consists of several problems which could ends in a failed project. Problems such as a totally underrated situation in the recipient country, etc. can be avoided, due to the fact that this problem is now under consideration. However, the consideration of the identified determinants of offset success is not a guarantee that it comes not to problems in project execution as a result of unpredictable factors, such as personal animosity, and so on.

For a further research on the offset-specific reasons for the failing of such projects and the determinants of offset success to avoid these problems could be of interest a more detailed examination which examined the different sides in the offset context (selling-, buying- and participating-side).

\section{References}

BIS - Bureau of Industry and Security (2007). Offsets in Defence Trade. Thirteenth Study. Washington, D.C.: BIS, U.S. Department of Commerce. Retrieved from http://www.bis.doc.gov/defenseindustrialbaseprograms/osies/ offsets/default.htm (accessed 13 July 2009).

Brauer, Jurgen. (2002). Economic Aspects of Arms Trade Offsets. Unpublished paper. Retrieved from http://www.aug.edu/ sbajmb/paper-offsets.PDF (accessed 22 February 2003)

Economist (2013). Guns and sugar. Online Article, May 25th 2013 | NEW YORK Retrieved from http://www.economist.com/news/business/21578400-more-governmentsare-insisting-weapons-sellers-invest-side-deals-help-them-develop. (accessed 22 June 2014)

Hall, P., \& Stefan M. (1994). On the Normality and Abnormality of Offset Obligations. Defence and Peace Economics, 5, 173-188.

Harrison, A. (2002). Case study research. In: Essential Skills for Management Research, edited by David Partington, Sage Publications.

Hartley, K. (1995). Industrial Policies in the Defense Sector. In Hartley, K., \& Sandler, T. (Eds.), Handbook of Defence Economics. Amsterdam: Elsevier.

Hartley, Wyndham (2004). Arms-Offset Projects Fail to Deliver, in Business Day. Retrieved from http://www.bday.co.za (accessed 13 July 2009)

Lumpe, Lora (1994). Sweet Deals, Stolen Jobs. Originally published in The Bulletin of the 


\section{Macrothink}

Business Management and Strategy

ISSN 2157-6068

2014, Vol. 5, No. 2

Atomic Scientists, September/October 1994. Retrieved from http://www.fas.org/asmp/library/articles/sweetdeals.htm (accessed 11 July 2011)

Neuman, S. G. (1985). Coproduction, Barter, and Countertrade: Offsets in the International Arms Market. Orbis, 29, Spring, 183-212.

SFFC - Swiss Federal Finance Controll (2007). Rüstungsbeschaffung im Ausland Evaluation der Kompensationsgeschäfte (Defense procurement abroad - Evaluation of compensation transactions). Retrieved from http://www.efk.admin.ch/images/stories/efk_dokumente/publikationen/evaluationen/Evaluati onen \%20\%2819\%29/6366BE_Bericht_23-06-08.pdf (accessed: 07 April 2014)

Tricolom (2014). Offset Management. Retrieved from http://www.tricolom.com/markets/ (accessed: March 22, 2014).

Udis, B., \& Maskus, K. (1991). Offsets as Industrial Policy: Lessons from Aerospace. Defence Economics, 2, 151-164.

Willett, Susan (1999). The Arms Trade, Debt \& Development. Available at: http://www.caat.org.uk/resources/publications/economics/debt-and-development-0599.php\#s ection1(accessed 23 June 2014).

\section{Internet Sources}

http://www.f-16.net/news_article2540.html

http://www.bbc.co.uk/polish/030306135405.shtml

http://konflikty.wp.pl/kat,115354,title,Dlaczego-kupilismy-F-16-choc-Gripen-dawal-lepszy-o ffset,wid,11747392,wiadomosc_wideo.html?ticaid=1caf0

http://www.bankier.pl/wiadomosc/Nadlecial-F-16-przetarg-stulecia-rozstrzygniety-584221.ht $\mathrm{ml}$

\section{Copyright Disclaimer}

Copyright reserved by the author.

This article is an open-access article distributed under the terms and conditions of the Creative Commons Attribution license (http://creativecommons.org/licenses/by/3.0/). 